\title{
Increased myocardial SERCA expression in early type 2 diabetes mellitus is insulin dependent: In vivo and in vitro data
}

Sabine Fredersdorf ${ }^{1,6^{*}}$, Christian Thumann ${ }^{1}$, Wolfram H Zimmermann ${ }^{2}$, Roland Vetter ${ }^{3}$, Tobias Graf ${ }^{4}$, Andreas Luchner ${ }^{1}$, Günter AJ Riegger ${ }^{1}$, Heribert Schunkert ${ }^{4}$, Thomas Eschenhagen ${ }^{5}$ and Joachim Weil ${ }^{4}$

\begin{abstract}
Background: Calcium (Ca2+) handling proteins are known to play a pivotal role in the pathophysiology of cardiomyopathy. However little is known about early changes in the diabetic heart and the impact of insulin treatment (Ins).

Methods: Zucker Diabetic Fatty rats treated with or without insulin (ZDF $\pm \ln s, n=13$ ) and lean littermates (controls, $n=7)$ were sacrificed at the age of 19 weeks. ZDF + Ins $(n=6)$ were treated with insulin for the last 6 weeks of life. Gene expression of Ca2+ ATPase in the cardiac sarcoplasmatic reticulum (SERCA2a, further abbreviated as SERCA) and phospholamban (PLB) were determined by northern blotting. Ca2+ transport of the sarcoplasmatic reticulum (SR) was assessed by oxalate-facilitated 45Ca-uptake in left ventricular homogenates. In addition, isolated neonatal cardiomyocytes were stimulated in cell culture with insulin, glucose or triiodthyronine (T3, positive control). mRNA expression of SERCA and PLB were measured by Taqman PCR. Furthermore, effects of insulin treatment on force of contraction and relaxation were evaluated by cardiomyocytes grown in a three-dimensional collagen matrix (engineered heart tissue, EHT) stimulated for 5 days by insulin. By western blot phosphorylations status of Akt was determed and the influence of wortmannin.

Results: SERCA levels increased in both ZDF and ZDF + Ins compared to control (control $100 \pm 6.2 \mathrm{vs.} \mathrm{ZDF}$ $152 \pm 26.6^{*}$ vs. ZDF + Ins $212 \pm 18.5^{*} \# \%$ of control, ${ }^{*} p<0.05$ vs. control, $\# p<0.05$ vs. ZDF) whereas PLB was significantly decreased in ZDF and ZDF + Ins (control $100 \pm 2.8$ vs. ZDF $76.3 \pm 13.5^{*}$ vs. ZDF + Ins $79.4 \pm 12.9^{*} \%$ of control, ${ }^{*} p<0.05$ vs control). The increase in the SERCA/PLB ratio in ZDF and ZDF \pm Ins was accompanied by enhanced Ca2+ uptake to the SR (control $1.58 \pm 0.1$ vs. ZDF $1.85 \pm 0.06^{*}$ vs. ZDF + Ins $2.03 \pm 0.1^{*} \mu \mathrm{g} / \mathrm{mg} / \mathrm{min}$, ${ }^{*} \mathrm{p}<0.05$ vs. control). Interestingly, there was a significant correlation between Ca2+ uptake and SERCA2a expression. As shown by in-vitro experiments, the effect of insulin on SERCA2a mRNA expression seemed to have a direct effect on cardiomyocytes. Furthermore, long-term treatment of engineered heart tissue with insulin increased the SERCA/PLB ratio and accelerated relaxation time. Akt was significantly phosphorylated by insulin. This effect could be abolished by wortmannin.
\end{abstract}

\footnotetext{
* Correspondence: sabine.fredersdorf@klinik.uni-r.de

${ }^{1}$ Klinik und Poliklinik für Innere Medizin II, Universität Regensburg,

Regensburg, Germany

${ }^{6}$ Klinik und Poliklinik für Innere Medizin II des Universitätsklinikums

Regensburg, 93042 Regensburg, Germany

Full list of author information is available at the end of the article
} 


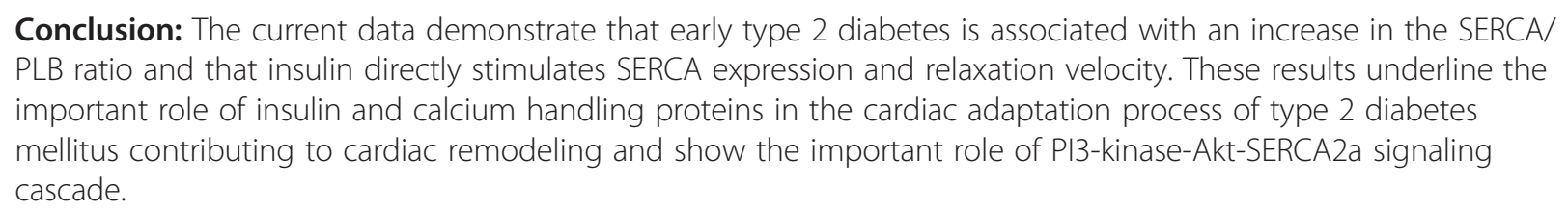

Keywords: Diabetic heart, Insulin, SERCA expression, Relaxation velocity

\section{Introduction}

The sarcoplasmatic reticulum (SR) plays a pivotal role in the contraction and relaxation cycle of the heart by virtue of its ability to tightly regulate intracellular calcium $(\mathrm{Ca} 2+)$ concentration. Myocardial contraction is initiated by $\mathrm{Ca} 2+$ entry through $\mathrm{Ca} 2+$ channels of the plasma membrane (L-type $\mathrm{Ca} 2+$ channel) [1] triggering the $\mathrm{Ca} 2+$ release from the SR through the ryanodine receptor. During diastole $\mathrm{Ca} 2+$ is transported from the cytoplasma into the SR by the SR Ca2+ATPase (SERCA). Recent cloning analysis revealed three distinct genes encoding for SR Ca2 + ATPases (SERCA 1-3), of which the SERCA2a is predominately expressed in cardiac tissue [2]. SERCA2a activity depends on the amount of SERCA2a protein and is further regulated by its inhibitory protein phospholamban (PLB) [3]. SERCA2a is the major determinant of the beat-to-beat regulation of cardiac contraction, and overexpression of this protein in mice has been shown to enhance myocardial relaxation [4]. Unphosphorylated PLB inhibits the Ca2+ uptake of SERCA2a and phosphorylation of the protein disrupts the inhibitory interaction resulting in increased $\mathrm{Ca} 2+$ transport towards the SR. Recent studies on PLB knockout mice have underlined the importance of PLB as a key regulator of cardiac contraction and relaxation [5].

While diabetes leads to cardiomyopathy in later stages with hypocontractility and reduced SERCA activity [6], we have observed increased contractility in earlier stages of type 2 diabetes mellitus [7]. Various animal models of diabetes have been used to study the causes and underlying subcellular events of diabetic cardiomyopathy. These studies suggest a dysfunctional sarcoplasmic reticulum (SR), leading to altered intracellular calcium handling in cardiac myocytes. This mechanism might be involved in the development of diabetic cardiomyopathy $[6,8]$. A reduced sequestration of calcium into the SR could readily explain the prolonged cardiac relaxation observed in diabetic cardiomyopathy. As a consequence, the SR calcium content declines, leading to a reduced systolic calcium release and therefore a weaker cardiac contraction. However, these studies were mainly carried out in models resembling insulin-dependent diabetes. Previous studies with diabetes type 1 models have shown a down-regulation of SERCA2a in the heart associated with a decrease in systolic and diastolic function. These functional alterations can be reversed by insulin treatment or SERCA2a overexpression [4,9]. So far, there is little information available on myocardial SERCA2a and PLB changes in the early stages of type 2 diabetes which is characterized by rather high insulin levels $[8,10,11]$.

The Zucker Diabetic Fatty rat (ZDF/Drt-fa) is characterized by early onset of hyperglycemia, hyperphagia, hyperinsulinemia, adiposity and hyperlipidemia, thereby resembling the clinical features of human type 2 diabetes [12]. In an earlier study, we were able to demonstrate that animals in transition from insulin resistance to type 2 diabetes but not lean control rats develop significant myocardial hypertrophy associated with increased systolic function as evaluated by echocardiography [7]. These findings raised the possibility that one or more proteins regulating intracellular calcium homeostasis may be altered in these animals. Therefore, the present study was designed to determine whether the cardiac phenotype of ZDF rats is associated with alterations in cardiac SR function and expression of SERCA2a and its regulating protein PLB. Since insulin treatment is widely used as a therapeutic option for patients with poorly controlled type 2 diabetes, its impact on the aforementioned proteins was studied in isolated cell preparations of the heart. Furthermore, we investigated the functional consequences of high insulin levels in an innovative engineered heart tissue model.

\section{Materials and methods}

\section{Animal model}

Male Zucker Diabetic Fatty rats (body weight (BW) range: $106-158 \mathrm{~g}, \mathrm{n}=13$ ) and male Zucker lean rats (BW 85-118 g, n=7) were obtained at the age of five weeks from Genetic Models (Indianapolis, USA). Animals were maintained on RMH-B rat chow from Hope Farms (Woerden, Netherlands) with water ad libitum. All animals were individually housed in a $12 \mathrm{~h}$ dark/light cycle controlled room. The protocol had been approved by the local committee on animal research and conforms to the Guide for the Care and Use of Laboratory Animals, published by the US National Institutes of Health (NIH Publication No. 85-23; revised 1985). At the age of 13 weeks, one week after developing hyperglycemia, the animals were divided into three groups: (1) Zucker 
lean rats (control group, $\mathrm{n}=7$ ), (2) Zucker Diabetic Fatty rats without insulin treatment (ZDF; $\mathrm{n}=7)$, and (3) Zucker Diabetic Fatty rats treated with insulin (ZDF + Ins; $\mathrm{n}=6$ ). Insulin treatment (Actrapid HM U500, Novo Nordisk, Mainz, Germany) was initiated at a dose of 25.0.

$\mathrm{U} / \mathrm{kg} /$ day with subcutaneously implanted Alzet osmotic minipumps (Model 2ML2 and 2ML4, Charles River Wiga, Sulzfeld, Germany). Pumps were changed after 2 weeks and the insulin dose was adapted to normalize blood glucose levels. Body weight was determined every week, and blood glucose levels every 2-3 weeks (Accu-Chek Plus Roche, Mannheim, Germany). At the age of 18 weeks, systolic blood pressure and heart rate were measured by indirect tail-cuff method as described [13] using an automated cuff inflator-pulse detection system (W+W electronic AG, BP recorder No. 8005, Basel, Switzerland). After 6 weeks of insulin treatment, at the age of 19 weeks, the animals were killed.

\section{Tissue preparation}

Hearts were rapidly excised, rinsed with saline and blotted dry. The whole heart weight was determined. The heart was dissected free from the atria, cut into right and left ventricular tissue, frozen in liquid nitrogen within 3 minutes and stored at $-80 \mathrm{C}$ until analyzed, as described earlier [7].

\section{Neonatal rat cardiac myocytes}

Rat cardiac myocytes were isolated from 1- to 3-day-old neonatal Wistar rats (University of Regensburg breed, from Charles River, Sulzfeld, Germany) as described earlier [14]. Briefly, hearts from 50-70 pups were minced and subjected to serial trypsin digestion to release single cells. After the final digestion, cells were washed and pre-plated for 1-2 h in complete culture medium (MEM supplemented with 10\% fetal calf serum and $1 \%$ penicillin/streptomycin). Unattached cells were pelleted and suspended in culture medium containing $0.1 \mathrm{mmol} / \mathrm{l} \mathrm{5} 5^{\prime}$-bromo-2'-desoxyuridine (BrdU) to suppress overgrowth of non- myoctes. Cells were then plated on culture dishes at a density of 150,000 cells/cm2 and incubated for 5 days at $37^{\circ} \mathrm{C}$ before being stimulated with insulin (0.1-3.0 $\mu \mathrm{mol} / \mathrm{l})$, wortmannin (300 and 1000 $\mathrm{nM})$ or triiodothyronine $(3.0 \mathrm{nmol} / \mathrm{l})$ as a positive control for up-regulation of SERCA2a mRNA expression [15].

\section{Engineered heart tissues}

Engineered heart tissues (EHT) were prepared as described previously [16]. Briefly, circular EHT were prepared by mixing freshly isolated cardiac myocytes from neonatal rats with collagen type 1 prepared from rat tails, a basement membrane mixture (Matrigel, tebu, Offenbach, Heidelberg, Germany), and concentrated serum containing culture medium (2xDMEM, 20\% horse serum, $4 \%$ chicken embryo extract, $200 \mathrm{U} / \mathrm{ml}$ penicillin and $200 \mu \mathrm{g} / \mathrm{ml}$ streptomycin); $\mathrm{pH}$ was neutralized by titration with $\mathrm{NaOH}(0,1 \mathrm{~N})$. The reconstitution mix was pipetted into circular casting molds and incubated for 30 to $45 \mathrm{~min}$ at $37 \mathrm{oC}$ and $5 \% \mathrm{CO} 2$ to allow hardening of the reconstitution mix. Thereafter, $5 \mathrm{ml}$ serumcontaining culture medium (DMEM, 10\% horse serum, $2 \%$ chicken embryo extract, $100 \mathrm{U} / \mathrm{ml}$ penicillin and $100 \mu \mathrm{g} / \mathrm{ml}$ streptomycin) was added to each dish. Culture was performed as described earlier [16]. After 7 days in culture, EHTs were transferred to a stretch device and subjected to phasic stretch (to $110 \%$ of their original length) for 5 days. Culture medium was changed 12 hours after EHT casting and then every other day. After transfer to the stretch device, the culture medium was changed every day and supplemented with insulin at a high physiological concentration $(0.1 \mu \mathrm{g} / \mathrm{ml}$; SigmaAldrich, Taufkirchen, Germany).

\section{Force measurement}

After 12 days ( 7 days in casting molds and 5 days of stretching), the EHTs were transferred to thermostated organ baths containing gassed Tyrode's solution and subjected to isometric force measurement as described elsewhere [16]. Briefly, electrically stimulated EHTs $(2 \mathrm{~Hz})$ were stretched to the length at which force of contraction was maximal and inotropic and lusitropic responses to cumulative concentrations of isoprenaline $(0.1-1000 \mathrm{nM})$ in the presence of $0.2 \mathrm{mM}$ calcium were recorded. Contractile activity was evaluated with a PCassisted system (BMON2, Ingenieurbüro Jäckel, Hanau, Germany).

\section{RNA analysis}

Total RNA from left ventricles or cultured cardiac myocytes was isolated with Trizol $^{\circledR}$ (Canadian Life Technologies Inc., Burlington, Ontario, Canada) according to the manufacturer's instructions. The concentration was determined photometrically at $260 \mathrm{~nm}$. Total RNA was stored at $80^{\circ} \mathrm{C}$. For Northern blot analysis $20 \mu \mathrm{g}$ of total RNA were denatured, sizefractionated by electrophoresis on $1 \%$ agarose gels under denaturing conditions, transferred to nylon membranes (Gene Screen Plus, NEN, Dreieich, Germany) and immobilized by ultraviolet irradiation. Blots were prehybridized and hybridized using standard protocols as described previously [17]. Hybridized filters were washed and exposed at $-80 \mathrm{C}^{\circ}$ to $\mathrm{x}$-ray films (XAR-5, Eastman Kodak, N.Y., USA) by using intensifying screens. Different exposures of all autoradiograms were obtained to ensure that laser scanning (Personal 
Densitometer No. 50301, Molecular Dynamics) was performed within the linear range of densitometry. For hybridization cDNA probes for rat SERCA, PLB (kindly gifted by K.R. Boeheler) and GAPDH were radiolabelled with $\alpha 32-\mathrm{P}$ dCTP (specific activity $3000 \mathrm{Ci} / \mathrm{mmol}$, Amersham, Dreieich, Germany) for Northern blot analysis. Values were normalized to these house-keeping gene GAPDH. The rat cDNA of GAPDH was cloned by reverse transcriptase PCR using the following primers: forward 5'-CTTCACCACCATGGAGAAGG-3'; and reverse 5'-ATTGAGAGCAATGCCAGCC-3'.

For quantitative RT-PCR (qRT-PCR), total RNA was transcribed with SuperScriptII RT (Invitrogen, CA, USA). Individual samples of $20 \mathrm{ng}$ cDNA were amplified with AmpliTaqGold Polymerase (Applied Biosystems, CA, USA) utilizing gene specific primers and fluorogenic probes (5' FAM and 3' TAMRA; see below for complete primer/probe sequence information) in an ABI PRISM ${ }^{\circledR}$ 7900HT Sequence Detection System (Applied Biosystems). Probes were designed to cross exon/intron boundaries with primer annealing sites being located in the adjacent exons to eliminate the possibility of genomic DNA amplification. . Standard curves were performed in duplicate with serially diluted cDNA from neonatal rat heart tissue $(1.5-50 \mathrm{ng})$ to determine PCR efficiency, which was similar in all groups SERCA and Phospholamban expression were evaluated as SERCA/ PLB ratio and correlated to EHT twitch tension and relaxation time (T2). Quantification was performed by the standard curve and 2- $\Delta \Delta \mathrm{Ct}$ methods [18].

SERCA2a: forward primer $5^{\prime}$ - AGT GGC TGA TGG TGC TGA AA-3'.

reverse primer 5'- GCA CCC GAA CAC CCT TAC AT-3.

probe 5' FAM- TTA CTC CAG TAT TGC AGG CTC CAG GTA -TAMRA 3'.

PLB: forward primer 5'- GCA GCT GAG CTC CCA GAC TT-3.

reverse primer 5'- TTT CCA TGA TGC CAG GAA GAC-3'.

probe 5' FAM- CAC AGA AGC CAA GGC CTC CTA AAA GGA G -TAMRA 3'.

We checked $18 \mathrm{~S}$, GAPDH, and CSQ2 (data not shown). However, corrections are not necessary because we have determined PLB and SERCA from the same cDNA samples.

\section{Western blot analysis}

$20 \mu \mathrm{l}$ of cell suspension of the cardiomyocyte cell culture were separated on 10\% SDS-polyacrylamide gels. Gels were run andseparated proteins were transferred to nitrocellulose membranes in $50 \mathrm{mM}$ sodium phosphate buffer, $\mathrm{pH} 7.4$, for $20 \mathrm{~h}$ at $300 \mathrm{~mA}$, and $4^{\circ} \mathrm{C}$. Nitrocellulose sheets were incubated with a rabbit polyclonal anti-human antisera (Sigma) at a 1:2000 dilution. Phospho-Akt and Akt antibodies (1:1000, from New England Biolabs) were visualized colorimetrically by using horseradish peroxidase- (HRP) conjugated goat anti-rabbit immunoglobulin G at a 1:1000 dilution. After phospho-Akt blotting, the blot was stripped for $30 \mathrm{~min}$ at $50 \mathrm{oC}$ and then blotted for Akt, serving also as loading control. Apparent molecular weights were determined by using a prestained standard (kaleidoscope prestained standard, Biorad, USA).

\section{Oxalate-supported $\mathrm{Ca} 2+$ uptake}

Oxalate-supported SR Ca2+ uptake was measured in left ventricular homogenates as described previously [19]. Briefly, the $\mathrm{Ca} 2+$ uptake medium of $0.2 \mathrm{ml}$ contained $40 \mathrm{mmol} / \mathrm{l}$ imidazole (pH 7.0), $100 \mathrm{mmol} / \mathrm{l} \mathrm{KCl}$, $5 \mathrm{mmol} / \mathrm{l} \mathrm{MgCl} 2,5 \mathrm{mmol} / \mathrm{l}$ TrisATP, $6 \mathrm{mmol} / \mathrm{l}$ phosphocreatine, $10 \mathrm{mmol} / \mathrm{l} \mathrm{K}+$-oxalate, $10 \mathrm{mmol} / \mathrm{l} \mathrm{NaN} 3$, $10 \mu \mathrm{M}$ synthetic protein kinase A-inhibitor peptide [PKI (6-22)amide; GIBCO-BRL, Eggenstein, Germany], $0.2 \mathrm{mmol} / \mathrm{l} \mathrm{EGTA}$, and 0.08 or $0.250 \mathrm{mmol} / \mathrm{l} 45 \mathrm{CaCl} 2$ corresponding to 0.34 or $3.68 \mu \mathrm{mol} / \mathrm{l}$ free $\mathrm{Ca} 2+$, respectively After $2 \mathrm{~min}$ of preincubation at $37^{\circ} \mathrm{C}$, the measurement was started by addition of homogenate $(30 \mu \mathrm{g}$ protein) and 2 min later a $0.15-\mathrm{ml}$ sample was filtered through 0.45- $\mu \mathrm{m}$ Millipore filters using a vacuum pump. The filter was immediately washed twice with $3 \mathrm{ml}$ ice-cold solution containing $100 \mathrm{mM} \mathrm{KCl}, 2 \mathrm{mM}$ EGTA, and $40 \mathrm{mM}$ imidazole ( $\mathrm{pH}$ 7.0). Radioactivity bound to dry filters was determined by liquid scintillation counting. All measurements were done in duplicate Ca uptake was measured within the linear range of the reaction. Calculated $\mathrm{Ca} 2+$ uptake values were expressed as nmoles of $\mathrm{Ca} 2+$ per $\mathrm{mg}$ of protein per min or $\mu$ moles of $\mathrm{Ca} 2+$ per $\mathrm{g}$ wet $\mathrm{LV}$ wt min.

\section{Statistics}

Statistical analysis was performed using GraphPad PRIZM 5.0. Results are expressed as mean \pm SEM. Comparisons between multiple groups were assessed by one-way analysis ANOVA-test and post-hoc analysis by Bonferroni. The strength of the relationship between two variables was assessed by calculating the productmoment correlation coefficient $r$. Statistical significance was accepted at $\mathrm{p}<0.05$.

\section{Results}

\section{Diabetic animals}

The ZDF rats developed a manifest diabetes at the age of 12 weeks (Capillary Glucose control group $78 \pm 1.8 \mathrm{mg} / \mathrm{dl}$ vs. ZDF $252 \pm 39^{*} \mathrm{mg} / \mathrm{dl}$ vs. ZDF + Ins $292 \pm 33^{*} \mathrm{~g} / \mathrm{dl}^{*}, \mathrm{p}<0.05$ vs. control). Body weight in ZDF rats increased steadily over time compared to nondiabetic lean animals. Treatment with insulin led to a further increase in body weight three weeks after 
beginning treatment (see Table 1). Absolute heart weight was significantly higher in the treatment group, but not in non-treated ZDF rats compared to age- matched ZDF rats (see Table 1). As expected, treatment with insulin decreased blood glucose level towards normoglycemic values in diabetic animals (see Table 1). Plasma Cpeptide-levels were markedly elevated in diabetic ZDF rats indicating severe hyperinsulinemia. Interestingly, heart rate was significantly lower in all diabetic animals and blood pressure was the same in the non-treated ZDF group and even reduced in the insulin-treated ZDF group (at 19 weeks of age: control $484 \pm$ min- 1 vs. ZDF $416 \pm 13^{*}$ min-1 vs. ZDF + Ins $421 \pm 18^{*} \min -1$, " $\mathrm{p}<0.05$ vs. control).

\section{Expression levels of SERCA and phospholamban (PLB)} SERCA2a detected a single mRNA of about $4.0 \mathrm{~kb}$. The PLB probe hybridized with two mRNA species of approximately 3.0 and $1.3 \mathrm{~kb}$ (Figure 1A). As shown in Figure 1B SERCA2a mRNA levels were significantly higher in diabetic compared to non-diabetic animals and showed a trend towards a further in crease in insulintreated animals (both $\mathrm{p}<0.05$ vs control). In contrast PLB mRNA levels were significantly reduced both in $\mathrm{ZDF}$ and $\mathrm{ZDF}+$ Ins (both $\mathrm{p}<0.05$ vs control). This led to an increase in the relative SERCA2a/PLB ratio (Figure 1c), indicating a facilitated intracellular calcium reuptake. Interestingly, treatment with insulin led to a further increase in SERCA2a mRNA in diabetic animals. To determine whether insulin directly up-regulates SERCA2a mRNA, isolated cardiac myocytes were treated with insulin over 5 days. As expected triiodothyronine (positive control) increased SERCA2a mRNA levels by approximately $75 \%$ as assessed by quantitative RT-PCR and had no effect on PLB expression (Figure 2A). Insulin led to a concentration-dependent increase in SERCA2a and PLB Fredersdorf et al. - Expression of SR Ca++- uptake regulating proteins in the diabetic heart 11 expression (Figure 2B). Interestingly, SERCA2a expression was already increased at lower insulin concentrations

Table 1 Biometric data at 19 weeks

\begin{tabular}{lccc}
\hline Characteristics & Control $(\mathbf{n}=\mathbf{7})$ & ZDF $(\mathbf{n}=\mathbf{7})$ & ZDF + Ins $(\mathbf{n}=\mathbf{6})$ \\
\hline BW (g) & $353 \pm 11$ & $402 \pm 9^{*}$ & $478 \pm 25^{*}$ \\
HW (mg) & $1372 \pm 33$ & $1341 \pm 46$ & $1530 \pm 53 \#$ \\
Rel. HW (mg/g BW) & $4.1 \pm 0.2$ & $3.3 \pm 0.1^{*}$ & $3.2 \pm 0.4^{*}$ \\
Serum glucose & $96 \pm 7$ & $477 \pm 26^{*}$ & $251 \pm 73^{*}$ \\
C-peptide (pmol/l) & $593 \pm 98$ & $913 \pm 65^{*}$ & $639 \pm 162^{\#}$ \\
Hb1Ac (\% of control) & $100 \pm 4$ & $301 \pm 12^{*}$ & $179 \pm 19^{*} \#$ \\
\hline
\end{tabular}

ZDF = Zucker Diabetic Fatty rats, Ins = insulin, BW = body weight, HW = heart weight.

${ }^{*} p<0.05$ vs control and \#p $<0.05$ vs. ZDF.

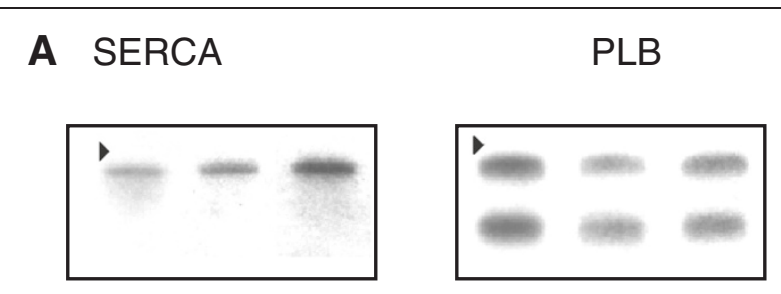

B

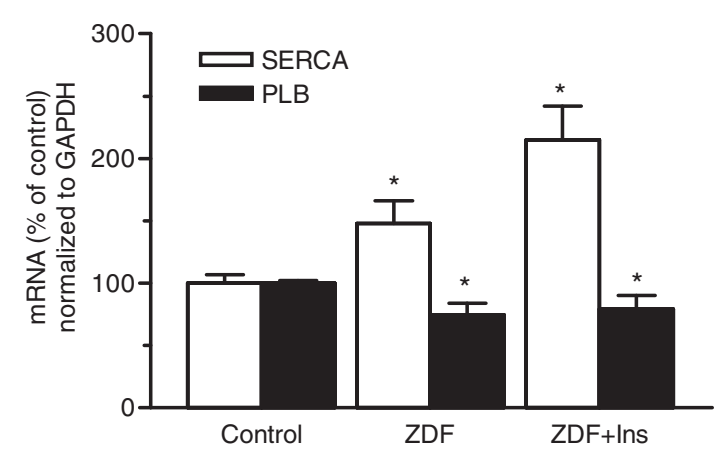

C

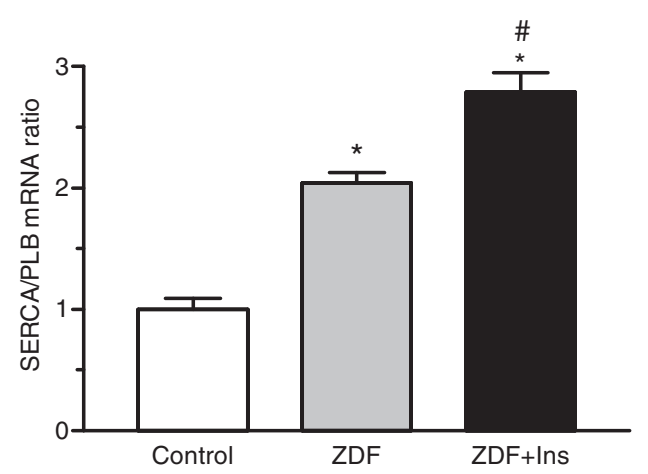

Figure 1 In vivo data: Expression of SERCA 2a and PLB in left ventricular tissue from non-diabetic control rats $(n=7)$, Zucker Diabetes Fatty (ZDF) rats $(n=7)$ and ZDF $(n=6)$ rats treated with insulin. (A) Shows a representative Northern blot of SERCA and phospholamban (lane $1=$ left ventricular tissue from control rats, lane 2 = left ventricular tissue from diabetic ZDF rats; lane $3=$ left ventricular tissue from ZDF rats treated with insulin). Arrow depicts the position of the $28 \mathrm{~S}$ ribosomal RNA. (B) quantitative analysis and (C) SERCA2a/PLB ratio. Values are given in mean \pm SEM. ${ }^{*} p<0.05$ vs. control; \#p $<0.05$ vs. ZDF.

(0.1-0.3 $\mu \mathrm{mol} / \mathrm{L})$ whereas PLB was unchanged. However, at higher insulin concentrations we found a similar increase in SERCA2a and PLB expression.

\section{Ca2 + -transport of myocardial sarcoplasmatic reticulum}

To test whether the aforementioned changes in SERCA2a and PLB affect Ca2+ uptake of the sarcoplasmatic reticulum we measured oxalate-supported $\mathrm{Ca} 2+$ uptake in homogenates from left ventricular tissue of diabetic and non-diabetic animals. Ca2+ uptake was significantly higher in diabetic animals compared to non-diabetic animals (Figure 3A). Treatment with insulin further 


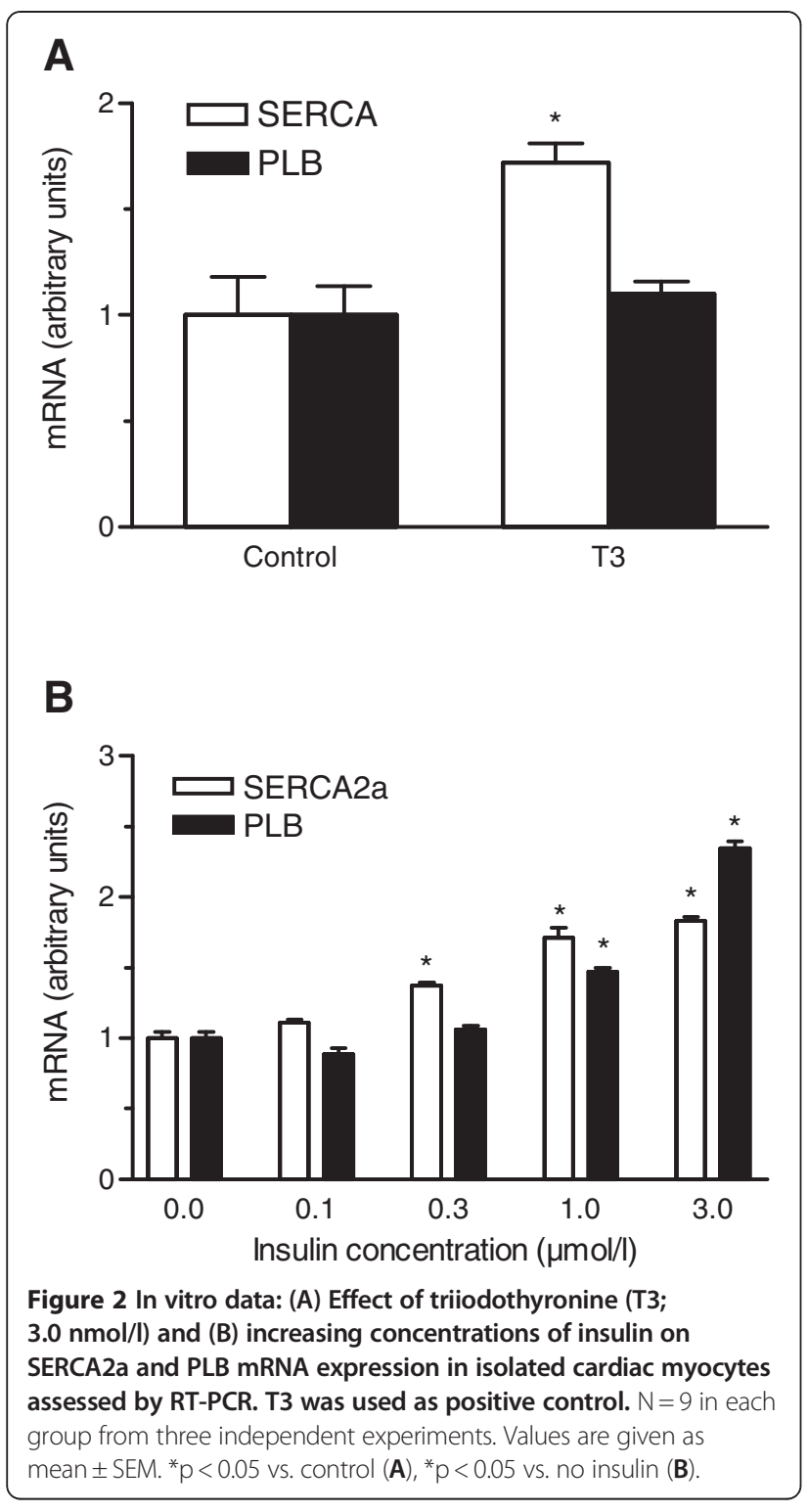

augmented $\mathrm{Ca} 2+$ uptake. As shown in Figure 3B there was a close relationship between myocardial SERCA2a mRNA expression and the calcium transport rate supporting the notion that insulin directly modifies SERCA2a mRNA expression in the heart.

\section{Effect of insulin on myocardial function in vitro}

Engineered heart tissue (EHT) chronically stimulated (5 days) with insulin in a supra-physiological concentration $(0.1 \mu \mathrm{g} / \mathrm{mL})$ revealed a significant increase in the SERCA2a/PLB ratio as determined by quantitative RTPCR (Figure $4 \mathrm{~A}$ ).

To determine the influence of the observed changes in the SERCA2a/PLB ratio on myocardial function contractile parameters of electrically driven control EHTs and insulin-stimulated EHTs were measured. Isometric

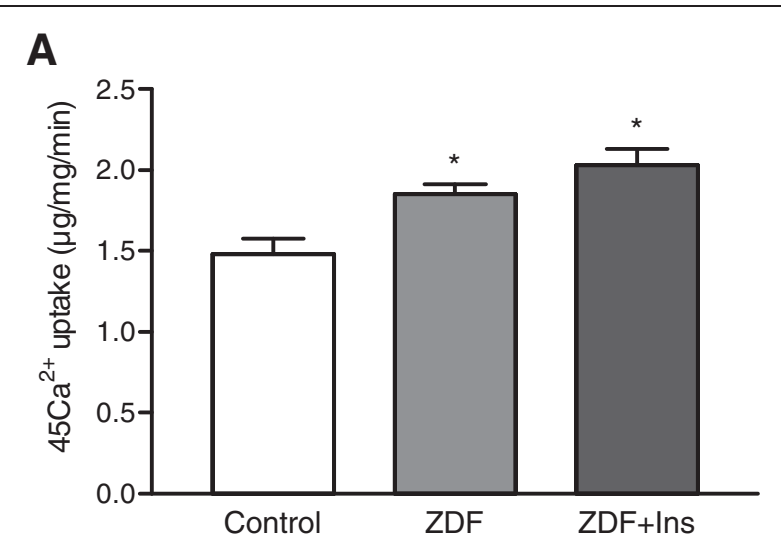

B

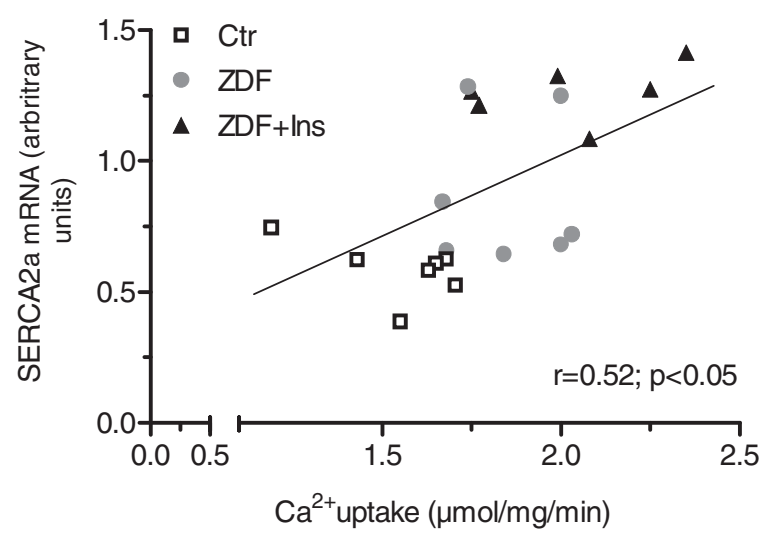

Figure 3 In vivo data: Differences in sarcoplasmic reticular $\mathrm{Ca} 2+$ uptake in left ventricular homogenates prepared from (A) non-diabetic control rats (control) $(n=7)$, Zucker Diabetes Fatty (ZDF) rats $(n=7)$ and ZDF rats treated with insulin (ZDF + Ins, $\mathbf{n}=\mathbf{6}$ ). (B) Relationship between calcium uptake and myocardial SERCA2a/PLB mRNA ratio. Ca2+ uptake was measured for 2 min in the presence of $3.68 \mu \mathrm{M}$ free $\mathrm{Ca} 2+$ concentrations. Values are given as mean \pm SEM. ${ }^{*} \mathrm{p}<0.05$ vs. control.

force development at optimal length in the absence $(0.75 \pm 0.12$ vs. $0.78 \pm 0.11 \mathrm{mN}, \mathrm{n}=7+10 ; \mathrm{p}=\mathrm{NS})$ and presence $(1.32 \pm 0.13$ vs. $1.42 \pm 0.08 \mathrm{mN}, \mathrm{n}=7+10$; $\mathrm{p}=\mathrm{NS})$ of isoprenaline $(1 \mu \mathrm{mol} / \mathrm{L})$ was not significantly different between control EHTs and insulin-stimulated EHTs (EHT $1.32 \pm 0.13$ vs. EHT + Ins $1.4 \pm 0.14 \mathrm{mN}$ $\mathrm{p}=\mathrm{NS}$ ). Interestingly, EHT relaxation (T2) was shorter in insulin treated EHTs (sustained positive lusitropic effect) under baseline conditions (EHT $105 \pm 3 \mathrm{~ms}$ vs. EHT + Ins $92 \pm 4 \mathrm{~ms}, \mathrm{n}=8-10 ; \mathrm{p}<0.05$ vs. EHT) and under maximal isoprenaline stimulation (EHT $88 \pm 2 \mathrm{~ms}$ vs. EHT + Ins $78 \pm 2 \mathrm{~ms}, \mathrm{n}=8-10 ; \mathrm{p}<0.05$ vs EHT; Figure $4 \mathrm{~B})$. In contrast, time to peak contraction was not affected by chronic insulin stimulation (data not shown).

Ultimately, the sustained lusitropic effect of insulin of isoprenaline as depicted in Figure 4B was considerably 


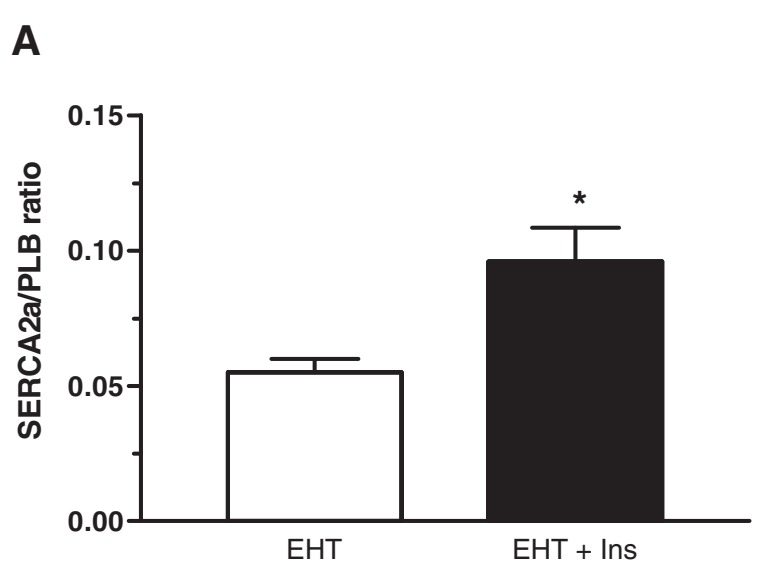

B

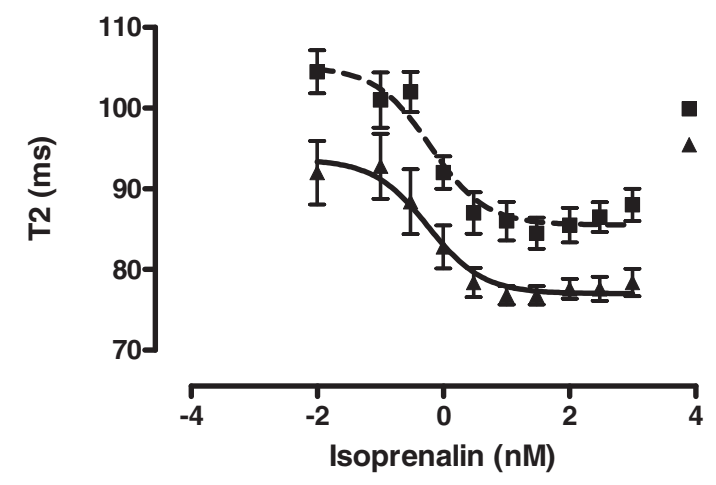

C

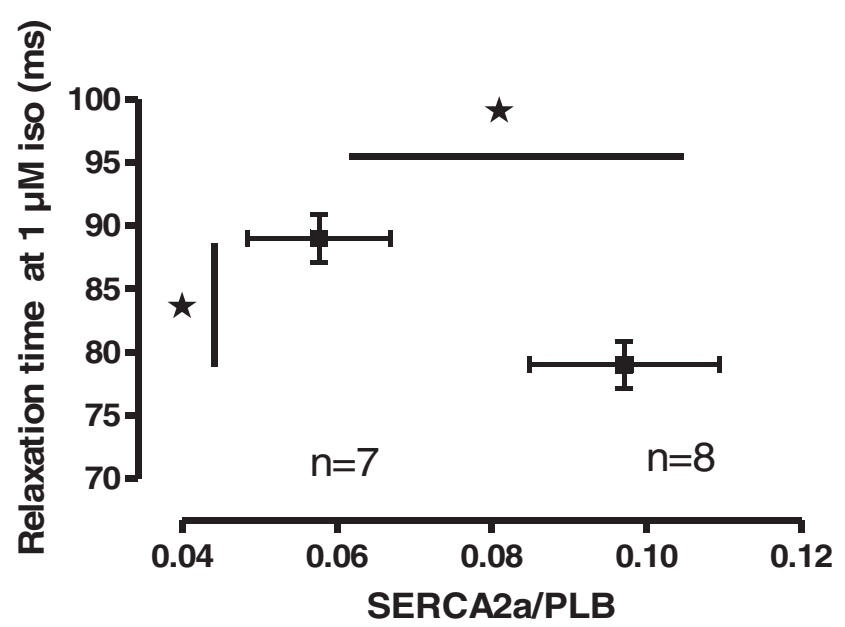

Figure 4 In vitro data: Effect of insulin on SERCA2a/PLB mRNA ratio (A) and (B) EHT relaxation data (T2). EHT were stimulated for 5 days with $0.10 \mu \mathrm{g} / \mathrm{mL}$ insulin over 5 days $(n=7-10)$ in each group from two independent cell preparations. Transcript concentration was determined by mRNA was measured by quantitative RT-PCR. ${ }^{*} p<0.01$ vs. EHT. (C) Correlation between relaxation time and SERCA2a/PLB ratio in EHT's without and with prior stimulation of insulin. Contractile response of isoprenaline $(1 \mu \mathrm{mol} / \mathrm{L})$ was determined under isometric conditions and in the presence of $0.2 \mathrm{mmol} / \mathrm{L}$ calcium ( $n=7-8$ in each group from two independent cell preparations). For clarity, only mean values $\pm S E M$ of the two groups are shown. ${ }^{*} \mathrm{p}<0.05$ vs. non insulin treated EHTs. In (B) relaxation time (T2) was significantly shorter in insulin stimulated EHTs $(p<0.05)$. 
enhanced in EHTs treated with insulin compared to control EHTs. Interestingly, there was a significant correlation between the isoprenaline induced relaxation and the higher SERCA2a/PLB ratio (Figure 4C). The latter was the result of a higher SERCA2a concentration and at the same time lower PLB transcript concentration Notably, absolute PLB transcript abundance was markedly lower in insulin treated EHTs when compared to control EHTs.

\section{Effect of insulin on akt}

As shown by Figure 5, Akt was significantly phosphorylated by insulin (B) in cardiomyocytes. Unphosphorylated Akt blot served as control (A). This effect could be abolished by wortmannin $(\mathrm{C})$ at higher wortmannin concentrations $(1000 \mathrm{nM})$ for every insulin stimulation, at lower wortmannin concentration $(300 \mathrm{nM})$ only for lower insulin concentrations.

\section{Discussion}

The key findings of this study are that in the early stages of type 2 diabetes, myocardial expression of SERCA2a is markedly elevated, whereas the expression of PLB mRNA is reduced. These changes go along with a significant increase in sarcoplasmatic $\mathrm{Ca} 2+$ uptake. Interestingly, the SERCA/PLB ratio in diabetic animals was further increased by insulin treatment. In vitro, we were able to demonstrate that insulin treatment of isolated cardiac myocytes led to a concentration-dependent increase in SERCA2a expression. This effect was also seen in a more complex model of engineered heart tissue and correlated positively with cardiac relaxation in vitro. . In addition, Akt was significantly stimulated by insulin in cardiomyocyte cell culture. This approach allows us to directly determine contractile alterations caused by insulin treatment without considering insulin-related systemic changes which might also affect the cardiovascular system. However we must consider that in vitro data can not totally be compared to in vivo data. Nevertheless they give essential additional information. Together, this suggests that insulin, which is particularly elevated in premature type 2 diabetes mellitus, may be involved in the induction of SERCA2a mRNA expression and may be an early step in the pathogenesis of diabetic cardiomyopathy.

\section{Alterations of SERCA, PLB and ca uptake in diabetes mellitus}

Diastolic relaxation of the heart is mediated to a large extent by the uptake of $\mathrm{Ca} 2+$ into the sarcoplasmic reticulum. Several studies have shown that diabetic cardiomyopathy is associated with decreased contractility and impaired relaxation [19]. These changes have been attributed to a reduced ability to sequester calcium into the SR, which primarily determines the speed of cardiac relaxation. Consecutive experiments have shown that

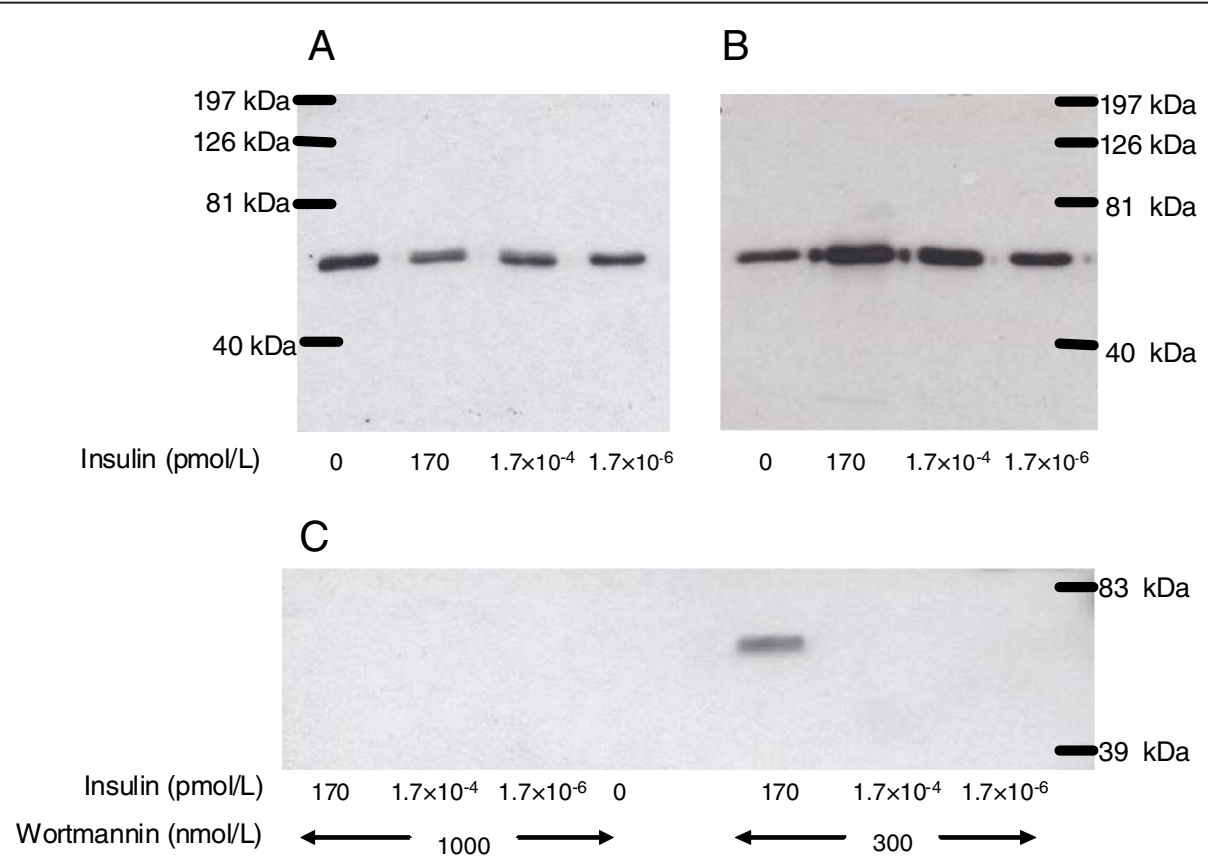

Figure 5 Effect of increasing concentrations of insulin on the phosphorylation status of Akt in isolated cardiomyocytes. (A) Western blot incubated with a specific antibody directed to total Akt. (B) The identical Western blot incubated with a specific antibody directed to phospho-Akt (Ser473). The insulin- mediated increase of phosphorylated Akt was abolished by the administration of an intermediated concentration of the PI3K-Inhibitor Wortmaninn, where Wortmaninn per se had no effect on phospho-Akt (C). 
SERCA2a mRNA expression, protein level and activity is down-regulated in streptozotocin-induced (STZ) type 1 diabetes mellitus $[10,11]$. In another model Wold and co-workers demonstrated in cardiomyocytes of rats with sucrose-induced insulin resistance that impaired SERCA activity with normal protein content contributes to cardiomyocyte dysfunction, whereas NCX function and expression are normal [20]. The authors concluded that subtle changes in $\mathrm{Ca} 2+$ regulation which occur prior to overt ventricular dysfunction and/or failure, may be common to early stages of a number of disorders involving insulin resistance. Furthermore, it has been demonstrated that reduced $\mathrm{Ca} 2+$ signaling in vascular smooth muscle cells from diabetic animals is related to a decline and/or redistribution in the IP3R $\mathrm{Ca} 2+$ channels and SERCA proteins. These changes could be repeated in cell culture experiments with high glucose levels [21]. The mechanism of alteration of SR proteins in STZinduced diabetes, however, is unclear at present. The same is true for the Otsuka-Long-Evans Tokushima Fatty rats (OLETF), a type 2 diabetes model. Here in late stages of diabetes, after additional sucrose feeding, the ventricular relaxation rate was significantly slower and was associated with reduced SERCA2a level [22]. These experiments are therefore in apparent contrast to our results. This discrepancy is most likely due to the different models used and the rather advanced duration of the diabetes and older age (60 weeks in the latter experiments as compared to 19-week-old diabetic rats in our study). OLETF rats present a milder form of diabetes mellitus with later onset and milder hyperglycemia at the beginning [23]. We examined ZDF rats at earlier diabetic stages, and our previous experiments have shown that C-peptide levels are high at this age [7].

\section{Insulin directly up-regulates SERCA and preserves cardiac function}

Most of the previous studies used a model with type 1 diabetes which differs fundamentally in pathophysiology. Whereas type 1 diabetes mellitus results from selective destruction of the insulin- producing beta cells of the pancreas, type 2 diabetes is primarily characterized by insulin resistance followed by progressive beta-cell dysfunction, resulting in low insulin levels in the long term. As recently shown, obese ZDF rats are insulin-resistant and have basal hyperinsulinemia that is due mainly to hypersecretion of insulin, as indicated by their elevated basal C-peptide levels $[7,24]$. Obese pre- diabetic and diabetic rats also show a reduction in insulin clearance, as indicated by their lower C- peptide/insulin ratio. Interestingly, the decrease in SERCA2a activity in STZtreated rats can be reversed by insulin treatment $[9,11]$, suggesting a direct stimulatory effect of insulin on SERCA2a. This hypothesis is further supported by other experiments demonstrating an up-regulation of SERCA1 in skeletal muscle after stimulation with insulin [1] These observations demonstrate a possible link between insulin and expression of SR calcium ATPase, which is further confirmed by the present in vitro studies showing a direct effect of insulin on SERCA2a transcription in isolated cardiac myocytes. The important role of insulin for heart function is further supported by Kim et al., who showed that insulin preserves heart function in streptozotocin-induced diabetic heart failure with and without transplantation of smooth muscle cells [25].

In this context it has been shown that transgenic (TG) mice with cardiac-specific overexpression of active Akt not only exhibit hypertrophy and enhanced left ventricular function but also show a 6.6-fold increase in SERCA2a protein levels, which could be recapitulated in vitro by adenovirus-mediated overexpression of Akt in cultured adult ventricular myocytes [26]. We demonstrated on isolated cardiac myocytes a strong and rapid phosphorylation of Akt after stimulation with insulin. Conversely, inhibiting SERCA2a with either ryanodine or thapsigargin affected myocyte contraction and relaxation and $\mathrm{Ca} 2+$ channel kinetics more in TG than in WT. Thus, myocytes from mice with overexpressed Akt demonstrated enhanced contractility and relaxation, Fura-2 $\mathrm{Ca} 2+$ transients, and $\mathrm{Ca} 2+$ channel currents [26]. Furthermore, increased protein expression of SERCA2a plays an important role in mediating enhanced left ventricular function by Akt. Interestingly, insulin stimulation led to a significant increase in SERCA2a, co-immunoprecipitated with insulin receptor substrate proteins (IRS-1 and IRS-1) in isolated cardiac muscle demonstrating a link between insulin, insulin receptor and SERCA2a [27] in cardiac tissue.

Recent experiments showed that insulin-like growth factor 1 (IGF-1) activates multiple signaling pathways, which involve the activation of the phosphatidylinositol (PI)3-kinase and Akt [28]. It is well known that the PI3kinase-Akt cascade modulates diverse cellular functions. Furthermore, it has been shown that that IGF-I caused increases in myocyte contraction and relaxation function, increases in intracellular $\mathrm{Ca} 2+$ transients, and an upregulation of SERCA2a [29]. The same group demonstrated that transgenic mice with cardiac-specific overexpression of Akt showed an enhanced left ventricular function, associated with an increased expression of SERCA2a [30]. These data are in accord with the studies of von Lewinski and co-workers [31](4), who suggested that Akt contribute to the acute inotropic effect of IGF-I in myocytes from human failing hearts.

In the present study, the insulin induced increase in phosphorylated Akt in isolated cardiomyocytes was abolished by the PI3-kinase inhibitor wortmannin, which provided evidence for a role of PI3-kinase. This finding 
suggests that the underlying cellular mechanism for up regulation of SERCA2a is mediated by the PI3-kinaseAkt-SERCA2a signaling cascade.

From a pathophysiological point of view, insulininduced up-regulation of myocardial SERCA2a may be seen as a feedback mechanism in handling the volume overload caused by high glucose levels in the early phase of type 2 diabetes, when insulin levels are high. With progression of the disease and decreasing levels of insulin the expression of SERCA2a in the heart becomes impaired. The reduction of SERCA2a, as typically seen in the late phase of type 2 diabetes, is a major cause of reduced diastolic and systolic function of the heart. This hypothesis is reinforced by the findings of Sakata et al. who demonstrated that cardiac SERCA2a gene transfer restores systolic and diastolic function to normal in diabetic rats [8]. Furthermore, in-vitro experiments provide evidence that high glucose levels also impair cytosolic $\mathrm{Ca} 2+$ removal involving slowed SR Ca2+ uptake. It has been speculated that slowed SR $\mathrm{Ca} 2+$ uptake results from depressed protein kinase A (PKA) down-regulating SERCA2a, rather than through depressed SERCA expression. Both expression and function of the $\mathrm{Na}-\mathrm{Ca}$ exchanger (NCX) appear to be normal in these experiments [16]. In summary, the up-regulation of SERCA2a in the early phase of type 2 diabetes is an important physiological adaptation of the heart allowing it to handle volume overload caused by high glucose levels.

\section{Competing interests}

The authors declare that they have no conflict of interest

\section{Authors' contributions}

SF carried out the molecular experiments and drafted the main parts of the manuscript. CT performed the work with the rats and northern blotting, WHZ supported us with the engineered heart tissue, RV performed the calcium uptake experiments, TG helped to draft the manuscript, AL participated in the design of the study and of the manuscript, GAJ participated in its design and coordination, HS helped to draft the manuscript, TH coordinated the molecular experiments and the engineered heart tissue model, JW conceived the study, performed the statistical analysis and drafted parts of the manuscript. All authors read and approved the final manuscript.

\section{Acknowledgments}

The authors wish to thank Sabine Laberer and Josef Simon for excellent technical assistance. This project was supported in part by a grant from the University of Regensburg to J. Weil and S. Fredersdorf (ReformA).

\footnotetext{
Author details

${ }^{1}$ Klinik und Poliklinik für Innere Medizin II, Universität Regensburg, Regensburg, Germany. ${ }^{2}$ Institut für Pharmakologie, Universitätsmedizin, Georg-August Universität Göttingen, Göttingen, Germany. Institut für Klinische Pharmakologie und Toxikologie, Universitätsmedizin - Berlin, Berlin, Germany. ${ }^{4}$ Medizinische Klinik II, Universitätsklinikum Schleswig-Holstein, Campus Lübeck, Lübeck, Germany. Institut für Klinische und Experimentelle Pharmakologie und Toxikologie, Universität Hamburg, Hamburg, Germany. ${ }^{6}$ Klinik und Poliklinik für Innere Medizin II des Universitätsklinikums Regensburg, 93042 Regensburg, Germany.
}

Received: 20 December 2011 Accepted: 2 May 2012

Published: 23 May 2012

\section{References}

1. Dibb KM, Graham HK, Venetucci LA, Eisner DA, Trafford AW: Analysis of cellular calcium fluxes in cardiac muscle to understand calcium homeostasis in the heart. Cell Calcium 2007, 42:503-512.

2. Frank KF, Bolck B, Erdmann E, Schwinger RH: Sarcoplasmatic reticulum Ca2+-ATPase modulates cardiac contraction and relaxation. Cardiovasc Res 2003, 57:20-27.

3. Periasamy M, Bhupathy P, Babu GJ: Regulation of sarcoplasmic reticulum Ca2+ ATPase pump expression and its relevance to cardiac muscle physiology and pathology. Cardiovasc Res 2008, 77:265-273.

4. Trost SU, Belke DD, Bluhm WF, Meyer M, Swanson E, Dillmann WH: Overexpression of the sarcoplasmic reticulum $\mathrm{Ca}(2+)$-ATPase improves myocardial contractility in diabetic cardiomyopathy. Diabetes 2002, 51:1166-1171.

5. Slack JP, Grupp IL, Dash R, Holder D, Schmidt A, Gerst MJ, Tamura T, Tilgmann C, James PF, Johnson R, Gerdes AM, Kranias EG: The enhanced contractility of the phospholamban- deficient mouse heart persists with aging. J Mol Cell Cardiol 2001, 33:1031-1040.

6. Ligeti L, Szenczi O, Prestia CM, Szabó C, Horváth K, Marcsek ZL, van Stiphout RG, van Riel NA, Op den Buijs J, Van der Vusse GJ, Ivanics T: Altered calcium handling is an early sign of streptozotocin-induced diabetic cardiomyopathy. Int J Mol Med 2006, 17:1035-1043.

7. Fredersdorf S, Thumann C, Ulucan C, Griese DP, Luchner A, Riegger GAJ, Kromer EP, Weil J: Myocardial Hypertrophy and Enhanced Left Ventricular Contractility in Zucker Diabetic Fatty Rats. Cardiovasc Pathol 2004, 13:11-19.

8. Sakata S, Lebeche D, Sakata Y, Sakata N, Chemaly ER, Liang LF, Padmanabhan P, Konishi N, Takaki M, del Monte F, Hajjar RJ: Mechanical and metabolic rescue in a type II diabetes model of cardiomyopathy by targeted gene transfer. Mol Ther 2006, 13:987-996.

9. Golfman L, Dixon IM, Takeda N, Chapman D, Dhalla NS: Differential changes in cardiac myofibrillar and sarcoplasmatic reticular gene expression in alloxan-induced diabetes. Mol Cell Biochem 1999, 200:15-25.

10. Zarain-Herzberg A, Yano K, Elimban V, Dhalla NS: Cardiac sarcoplasmatic reticulum Ca2+- ATPase expression in streptozotocin-induced diabetic rat. Biochem Biophys Res Comm 1994, 203:113-120

11. Zhong Y, Ahmed S, Grupp IL, Matlib MA: Altered SR protein expression associated with contractile dysfunction in diabetic rat heart. Am J Physiol Heart Circ Physiol 2001, 281:H1137-H1147.

12. Reed MJ, Scribner KA: In-vivo and in-vitro models of type 2 diabetes in pharmaceutical drug discovery. Diabetes, Obesity and Metabolism 1999, $1: 75-86$.

13. Peterson RG, Shaw WN, Neel MA, Little LA, Eichberg J: Zucker diabetic fatty rat as a model for non-insulin-dependent diabetes mellitus. ILAR News 1990, 32:16-19.

14. Weil J, Benndorf R, Fredersdorf S, Griese DP, Eschenhagen T: Norepinephrine upregulates vascular endothelial growth factor in rat cardiac myocytes by a paracrine mechanism. Angiogenesis 2003, 6:303-309.

15. Muller A, Zuidwijk MJ, Simonides WS, van Hardeveld C: Modulation of SERCA2 expression by thyroid hormone and norepinephrine in cardiocytes: role of contractility. Am J Physiol 1997, 272:H1876-H1885.

16. Zimmermann $W H$, Schneiderbanger $K$, Schubert $P$, Didié $M$, Münzel F, Heubach JF, Kostin S, Neuhuber WL, Eschenhagen T: Tissue engineering of a differentiated cardiac muscle construct. Circ Res 2002, 90:223-230.

17. Weil J, Eschenhagen T, Fleige G, Mittmann C, Orthey E, Scholz H: Localization of preproenkephalin mRNA in rat heart: selective gene expression in left ventricular myocardium. Am J Physiol 1998, 275: $\mathrm{H} 378-\mathrm{H} 384$

18. Livak KJ, Schmittgen TD: Analysis of relative gene expression data using real-time quantitative $P C R$ and the $2(-\Delta C t)$ method. Methods 2001 25:402-408.

19. Belke DD, Dillmann WH: Altered cardiac calcium handling in diabetes. Curr Hypertens Rep 2004, 6:424-429.

20. Wold LE, Dutta K, Mason MM, Ren J, Cala SE, Schwanke ML, Davidoff AJ: Impaired SERCA function contributes to cardiomyocyte dysfunction in insulin resistant rats. J Mol Cell Cardiol 2005, 39:297-307.

21. Searls YM, Loganathan R, Smirnova IV, Stehno-Bittel L: Intracellular Ca2+ regulating proteins in vascular smooth muscle cells are altered with type 1 diabetes due to the direct effects of hyperglycemia. Cardiovasc Diabetol 2010, 9:8. 
22. Abe T, Ohga Y, Tabayashi N, Kobayashi S, Sakata S, Misawa H, Tsuji T, Kohzuki H, Suga H, Tanigucchi S, Takaki M: Left ventricular diastolic dysfunction in type II diabetes mellitus model rats. Am J Heart Circ Physiol 2002, 282:H139-H148.

23. Yagi $\mathrm{K}$, Kim S, Wanibuchi H, Yamashita T, Yamamura Y, I wao H: Characteristics of diabetes, blood pressure, and cardiac and renal complications in Otsuka Long-Evans Tokushima Fatty rats. Hypertension 1997, 29:728-735.

24. Goh TT, Mason TM, Gupta N, So A, Lam TK, Lam L, Lewis GF, Mari A, Giacca A: Lipid-induced beta-cell dysfunction in vivo in models of progressive beta-cell failure. Am J Physiol Endocrinol Metab 2007, 292:E549-E560.

25. Kim BO, Verma S, Weisel RD, Fazel S, Jia ZQ, Mizuno T, Li RK: Preservation of heart function in diabetic rats by the combined effects of muscle cell implantation and insulin therapy. Eur J Heart Fail 2008, 10:14-21.

26. Kim YK, Kim SJ, Yatani A, Huang Y, Castelli G, Vatner DE, Liu J, Zhang Q, Diaz G, Zieba R, Thaisz J, Drusco A, Croce C, Sadoshima J, Condorelli G, Vatner SF: Mechanism of enhanced cardiac function in mice with hypertrophy induced by overexpressed Akt. Biol Chem 2003, 278:47622-47628.

27. Algenstaedt P, Antonetti DA, Yaffe MB, Kahn CR: Insulin receptor substrate proteins create a link between the tyrosine phosphorylation cascade and the Ca2+-ATPases in muscle and heart. J Biol Chem 1997, 272:23696-23702.

28. Ren J, Samson WK, Sowers JR: Insulin-like growth factor I as a cardiac hormone: physiological and pathophysiological implications in heart disease. J Mol Cell Cardiol 1999, 31:2049-2061.

29. Kim SJ, Abdellatif M, Koul S, Crystal GJ: Chronic treatment with insulin-like growth factor I enhances myocyte contraction by upregulation of AktSERCA2a signaling pathway. Am J Physiol Heart Circ Physiol 2008, 295:H130-H135.

30. Kim YK, Kim SJ, Yatani A, Huang Y, Castelli G, Vatner DE, Liu J, Zhang Q, Diaz G, Zieba R, Thaisz J, Drusco A, Croce C, Sadoshima J, Condorelli G, Vatner SF: Mechanism of enhanced cardiac function in mice with hypertrophy induced by overexpressed Akt. J Biol Chem 2003, 278:47622-47628.

31. Von Lewinski D, Voss K, Hulsmann S, Kogler H, Pieske B: Insulin-like growth factor-1 exerts $\mathrm{Ca} 2+-$ dependent positive inotropic effects in failing human myocardium. Circ Res 2003, 92:169-176.

doi:10.1186/1475-2840-11-57

Cite this article as: Fredersdorf et al:: Increased myocardial SERCA

expression in early type 2 diabetes mellitus is insulin dependent: In vivo and in vitro data. Cardiovascular Diabetology 2012 11:57

\section{Submit your next manuscript to BioMed Central and take full advantage of:}

- Convenient online submission

- Thorough peer review

- No space constraints or color figure charges

- Immediate publication on acceptance

- Inclusion in PubMed, CAS, Scopus and Google Scholar

- Research which is freely available for redistribution 